\title{
Efficacy of Nab-Paclitaxel as Second-line Chemotherapy for Unresectable or Recurrent Gastric Cancer
}

\author{
MINORU FUKUCHI, ERITO MOCHIKI, TORU ISHIGURO, TOSHIRO OGURA, JUN SOBAJIMA, \\ YOUICHI KUMAGAI, KEIICHIRO ISHIBASHI and HIDEYUKI ISHIDA \\ Department of Digestive Tract and General Surgery, Saitama Medical University, Kawagoe, Japan
}

\begin{abstract}
Aim: To evaluate the efficacy and safety of nanoparticle albumin-bound-paclitaxel (nab-PTX) as second-line chemotherapy (CT) for patients with unresectable or recurrent gastric cancer $(G C)$. Patients and Methods: The clinicopathological and survival data of 37 patients with unresectable or recurrent GC who underwent nab-PTX monotherapy as second-line CT, were retrospectively analyzed. Results: The median number of cycles and relative dose intensity administered per patient were 5 and 90\%, respectively. Their overall response rate was $24.3 \%$ and the disease control rate was $59.5 \%$. Median progression-free survival (PFS) and overall survival were 4.8 months and 10.4 months, respectively. Thirteen patients had grade 3 or 4 toxicities and were managed. In multivariate Cox regression analysis, cycles of chemotherapy $\geq 5$ (odds ratio, 0.20; 95\% confidence interval, 0.08-0.50; $p<0.01$ ) was the only significant independent predictor of longer PFS. Conclusion: Nab-PTX may effectively prevent disease progression as second-line CT by increasing treatment cycles and managing adverse effects.
\end{abstract}

Gastric cancer (GC) is the third leading cause of cancerrelated death worldwide. Although the GC mortality rate has decreased in many countries, it remains the second leading cause of cancer death in Japan (1). Advanced GC is generally treated with both surgery and chemotherapy (CT); unresectable or recurrent GC is treated with $\mathrm{CT}$ alone. In Japan, the SPIRITS trial, a phase-III study, established S-1 plus cisplatin as a standard first-line $\mathrm{CT}$ regimen for unresectable or recurrent GC (2). Several recent phase-III

Correspondence to: Minoru Fukuchi, MD, Department of Digestive Tract and General Surgery, Saitama Medical Center, Saitama Medical University, 1981 Kamoda, Kawagoe, Saitama 350-8550, Japan. Tel: +81 492283619, Fax: +81 492228865, e-mail: mfukuchi@saitama-med.ac.jp

Key Words: Gastric cancer, nab-paclitaxel, second-line chemotherapy, progression-free survival. studies showed a survival benefit with second-line CT compared with best supportive care (3-5). In Japan, paclitaxel (PTX) is the most commonly used second-line CT agent for unresectable or recurrent GC, and has shown overall response rates (ORR) of 16-27\%, overall survival (OS) times of 5-11 months and modest toxicity in several phase-II studies of advanced GC (6-9). With regard to OS, the recent phase-III WJOG trial failed to show CPT-11's superiority to weekly PTX (10).

PTX is insoluble in water and therefore had been dissolved in Cremophor EL (polyoxyethylene castor oil) and anhydrous ethanol; however, these vehicles have led to toxicity associated with PTX use. Nanoparticle albumin-bound paclitaxel (nabPTX) was created to resolve these vehicle-related problems by binding PTX to albumin and thereby making it soluble in physiological saline. Nab-PTX allows the safe infusion of significantly higher doses of PTX than those used in standard PTX therapy, with shorter infusion schedules (30 min vs. $3 \mathrm{~h}$ ) and no requirement of premedication for solvent-based hypersensitivity reactions. In Japan, nab-PTX has been established as a treatment for GC; results of a phase-II study were published in 2014 (11). However, the efficacy of nabPTX as second-line CT for unresectable or recurrent GC has not yet been clinically evaluated. In this study, we retrospectively examined the clinicopathological and progression-free survival (PFS) data of patients with unresectable or recurrent GC after failure of first-line CT to evaluate the efficacy and safety of $n a b$-PTX as second-line CT.

\section{Patients and Methods}

Patients. A database of 37 patients with unresectable or recurrent GC who underwent CT with nab-PTX after the failure of first-line CT at the Saitama Medical Center of the Saitama Medical University from September 2013 to October 2015, was retrospectively reviewed. Nab-PTX has been mainly selected as second-line CT for patients with unresectable or recurrent GC at this time. We evaluated the efficacy and safety of nab-PTX monotherapy and the outcomes in these 37 patients. This retrospective study was approved by the local ethics committee of Saitama Medical Center of Saitama Medical University (No. 613- II). 
Tumor classification and histopathological grading were performed according to the Union for International Cancer Control pTNM staging guidelines, seventh edition (12). Terminology defined by the Japanese Gastric Cancer Association was used to avoid unnecessary confusion (13). All patients had at least one proven lesion with any non-curative factor such as peritoneal (P1), hepatic (H1) and distant metastasis (M1). Additionally, eligible patients were required to have an Eastern Cooperative Oncology Group (ECOG) performance status (PS) of 0 or 1.

Chemotherapy schedule. Patients received a single infusion nabPTX $\left(260 \mathrm{mg} / \mathrm{m}^{2}\right)$ on an outpatient basis during a 30-minute period on day 1 of a 3 -week cycle (11). Treatment was discontinued at onset of disease progression, development of severe toxic effects, or patient's request. Three dose reduction levels $(220,180$, and $150 \mathrm{mg} / \mathrm{m}^{2}$ ) were implemented under the dose reduction criteria. Tumor response was objectively assessed after each treatment course according to the Response Evaluation Criteria in Solid Tumors. Adverse events were evaluated by the Common Terminology Criteria for Adverse Events, version 4.0.

Follow-up schedule. Disease progression and new lesion development were evaluated as needed by radiography and computed tomography. Tumor markers carcinoembryonic antigen and CA 19-9 were measured at baseline and at least every 4-6 weeks during treatment. Responses were evaluated every 6 weeks or earlier in patients with evidence of treatment failure. Physical examinations and laboratory tests were performed before treatment and at least every 3 weeks during treatment.

Statistical analysis. Continuous variables are expressed as medians and ranges. Grouping of categorical and continuous variables was carried out using standard thresholds. Cox proportional hazard regression analysis was used to identify significant independent factors for PFS. Factors for which $p<0.05$ according to univariate analysis were assessed by multivariate analysis. In the univariate and multivariate analyses, odds ratios (ORs) with 95\% confidence intervals (CIs) were calculated. All statistical analyses were performed with JMP 5.0 software (SAS Institute, Cary, NC, USA). $p<0.05$ was considered to be significant.

\section{Results}

Patients' characteristics. Characteristics of the 37 patients who underwent second-line CT with $n a b$-PTX are presented in Table I. These 37 patients included 27 men and 10 women with a median age of 65 years (range: $32-81$ years). Of the 37 patients, $26(70 \%)$ underwent gastrectomies. The most commonly prescribed agents prior $\mathrm{CT}$, were $\mathrm{S}-1$ monotherapy as adjuvant CT $(20 \%)$ or S-1 plus cisplatin as first-line CT (59\%). The respective median number of cycles was 5 (range: 2-16) and the relative dose intensity (RDI) administered per patient was $90 \%$ (range: 49-100\%), with $13(35 \%)$ and $16(43 \%)$ patients requiring dose reductions and delays, respectively.

Response. All 37 patients were assessable for response (Table II). Four patients (10.8\%) had complete responses (CR), five (13.5\%) had partial responses, thirteen (35.1\%)
Table I. Characteristics of 37 patients with unresectable or recurrent gastric cancer receiving nab-paclitaxel as second-line chemotherapy.

\begin{tabular}{|c|c|}
\hline \multicolumn{2}{|l|}{ Characteristic } \\
\hline Median age (range), years & $65(32-81)$ \\
\hline \multicolumn{2}{|l|}{ Gender, $\mathrm{n}$} \\
\hline Male/female & $27 / 10$ \\
\hline \multicolumn{2}{|l|}{ Performance status, $\mathrm{n}$} \\
\hline $0 / 1$ & $30 / 7$ \\
\hline \multicolumn{2}{|l|}{ Location, $\mathrm{n}$} \\
\hline $\mathrm{U} / \mathrm{M} / \mathrm{L}$ & $16 / 8 / 13$ \\
\hline \multicolumn{2}{|l|}{ Histological type, $\mathrm{n}$} \\
\hline $\mathrm{G} 1 / 2 / 3$ & $6 / 10 / 21$ \\
\hline \multicolumn{2}{|l|}{ Primary lesion, $\mathrm{n}$} \\
\hline Absent/present & $26 / 11$ \\
\hline \multicolumn{2}{|l|}{ Type of treatment failure, $\mathrm{n}$} \\
\hline First line/adjuvant & $28 / 9$ \\
\hline \multicolumn{2}{|l|}{ Number of non-curative factors, $\mathrm{n}$} \\
\hline $1 / 2 / 3$ & $25 / 10 / 2$ \\
\hline \multicolumn{2}{|c|}{ Organs of noncurative factor, $\mathrm{n}$ (overlapping) } \\
\hline Peritoneum & 13 \\
\hline Liver & 6 \\
\hline Lung & 8 \\
\hline Lymph node & 16 \\
\hline Others & 5 \\
\hline Median number of cycles (range) & $5(2-16)$ \\
\hline Relative dose intensity (range), $\%$ & $90(49-100)$ \\
\hline \multicolumn{2}{|l|}{ Adjuvant chemotherapy, $\mathrm{n}$} \\
\hline S-1 & 7 \\
\hline UFT & 2 \\
\hline \multicolumn{2}{|l|}{ First-line chemotherapy, $\mathrm{n}$} \\
\hline S-1 based & 26 \\
\hline Others & 2 \\
\hline \multicolumn{2}{|l|}{ Third-line chemotherapy, $\mathrm{n}$} \\
\hline Irinotecan & 10 \\
\hline Docetaxel & 3 \\
\hline Others & 3 \\
\hline
\end{tabular}

UFT, Tegafur-uracil.

Table II. Clinical responses of patients with unresectable or recurrent gastric cancer receiving nab-paclitaxel as second-line chemotherapy.

Characteristics

Complete response, $\mathrm{n}(\%)$

$4(10.8)$

Partial response, n (\%)

$5(13.5)$

Stable disease, $\mathrm{n}(\%)$

$13(35.1)$

Progressive disease, $\mathrm{n}(\%)$

$15(40.5)$

Overall response rate, $\%$

24.3

Disease control rate, $\%$

59.5

Median progression-free survival, months

Median overall survival, months

10.4

had stable disease and fifteen (40.5\%) had progressive disease. The overall response rate (ORR) was $24.3 \%$ and the disease control rate was $59.5 \%$. 
Table III. Univariate and multivariate predictors of progression-free survival in patients with unresectable or recurrent gastric cancer receiving nab-paclitaxel as second-line chemotherapy.

\begin{tabular}{|c|c|c|c|c|c|}
\hline \multirow[t]{2}{*}{ Variables } & \multirow[b]{2}{*}{$\mathrm{n}$} & \multicolumn{2}{|c|}{ Univariate } & \multicolumn{2}{|c|}{ Multivariate } \\
\hline & & Odds ratio $(95 \% \mathrm{CI})$ & $p$-Value & Odds ratio $(95 \% \mathrm{CI})$ & $p$-Value \\
\hline \multicolumn{6}{|l|}{ Age; years } \\
\hline$<65$ & 18 & $0.86(0.58-1.26)$ & 0.44 & & \\
\hline$\geq 65$ & 19 & 1 & & & \\
\hline \multicolumn{6}{|l|}{ Gender } \\
\hline Male & 27 & 1 & & & \\
\hline Female & 10 & $0.96(0.60-1.45)$ & 0.86 & & \\
\hline \multicolumn{6}{|c|}{ Performance status } \\
\hline 0 & 30 & $0.79(0.49-1.38)$ & 0.38 & & \\
\hline 1 & 7 & 1 & & & \\
\hline \multicolumn{6}{|l|}{ Location } \\
\hline $\mathrm{U} / \mathrm{M}$ & 24 & 1 & & 1 & \\
\hline $\mathrm{L}$ & 13 & $0.59(0.37-0.89)$ & 0.01 & $0.64(0.37-1.06)$ & 0.08 \\
\hline \multicolumn{6}{|c|}{ Histological type } \\
\hline $\mathrm{G} 1, \mathrm{G} 2$ & 16 & 1 & & & \\
\hline G3 & 21 & $0.73(0.34-1.59)$ & 0.43 & & \\
\hline \multicolumn{6}{|l|}{ Primary lesion } \\
\hline Absent & 26 & $0.63(0.41-1.00)$ & 0.05 & $0.70(0.44-1.13)$ & 0.15 \\
\hline Present & 11 & 1 & & 1 & \\
\hline \multicolumn{6}{|c|}{ No. of noncurative factors } \\
\hline 1 factor & 25 & $0.84(0.57-1.26)$ & 0.40 & & \\
\hline 2, 3 factors & 12 & 1 & & & \\
\hline \multicolumn{6}{|c|}{ Number of cycles } \\
\hline$<5$ & 18 & 1 & & 1 & \\
\hline$\geq 5$ & 19 & $0.21(0.09-0.48)$ & $<0.01$ & $0.20(0.08-0.50)$ & $<0.01$ \\
\hline \multicolumn{6}{|c|}{ Relative dose intensity; \% } \\
\hline$<90$ & 16 & $0.63(0.42-0.94)$ & 0.02 & $0.89(0.55-1.42)$ & 0.64 \\
\hline$\geq 90$ & 21 & 1 & & 1 & \\
\hline \multicolumn{6}{|l|}{ Toxicity } \\
\hline Grade 1,2 & 25 & $0.82(0.34-1.79)$ & 0.62 & & \\
\hline Grade 3,4 & 12 & 1 & & & \\
\hline
\end{tabular}

CI, Confidence interval.

Survival. Median PFS was 4.8 months, with a median follow-up time of 8.1 months (range: 2.0-24.9 months). Median OS was 10.4 months (Table III). Median duration of treatment was 89.0 days (range: 22-477 days).

We selected the following 10 variables for univariate analysis with regard to PFS: age ( $<65 v s . \geq 65$ years), sex (male vs. female), PS (0vs. 1), location (U or M vs. L), histologic type (G1 or 2 vs. G3), primary lesion (absent vs. present), number of noncurative factors (1 vs. 2, 3), cycles of CT ( $<5 v s . \geq 5)$, RDI ( $<90 v s . \geq 90 \%)$ and toxicity grade (grade 1 or $2 v s .3$ or 4 ). In univariate analysis, lower location $(p=0.01)$, absent primary lesion $(p=0.05)$, RDI $<90 \% \quad(p=0.02)$ and cycles of CT $\geq 5 \quad(p<0.01)$ were significantly associated with longer PFS. In multivariate Cox regression analysis, only cycles of $\mathrm{CT} \geq 5$ (OR, 0.20; $95 \% \mathrm{CI}=0.08-0.50 ; p<0.01)$ was an independent predictor of longer PFS (Table III).
Adverse effects. All patients reported at least one drug-related adverse effect (Table IV). Thirteen patients (35.1\%) had grade 3 or 4 toxicities with incidence rates of $\geq 10 \%$ included neutropenia $(21.6 \%)$, leukopenia $(10.8 \%)$ and grade $1-3$ toxicities included anemia $(97.3 \%)$ and peripheral sensory neuropathy $(91.9 \%)$.

\section{Discussion}

Patients with unresectable or recurrent GC usually have poor prognoses and generally undergo standard first-line CT. They may undergo second-line CT after the failure of first-line CT. In Japan, PTX is the most commonly used second-line agent for unresectable or recurrent GC; $n a b$-PTX has been similarly used. In two phase-II studies, PTX resulted in ORR of 16-27\%, and median OS of 5-8 months for advanced GC in second-line setting $(6,8)$. However, the efficacy of $n a b$ - 
Table IV. Adverse events related to nab-paclitaxel occurring in $\geq 10 \%$ of patients with unresectable or recurrent gastric cancer receiving as secondline chemotherapy.

\begin{tabular}{|c|c|c|c|c|c|c|}
\hline \multirow[t]{2}{*}{ Type } & \multicolumn{4}{|c|}{ Grade } & \multirow{2}{*}{$\begin{array}{c}\text { Grade } 1-4 \\
\text { n }(\%)\end{array}$} & \multirow{2}{*}{$\begin{array}{c}\text { Grade } 3 \text { or } 4 \\
n(\%)\end{array}$} \\
\hline & 1 & 2 & 3 & 4 & & \\
\hline \multicolumn{7}{|l|}{ Hematologic } \\
\hline Anemia & 24 & 12 & 0 & 0 & $36(97.3)$ & $0(0.0)$ \\
\hline Leukopenia & 2 & 4 & 4 & 0 & $10(27.0)$ & $4(10.8)$ \\
\hline Neutropenia & 1 & 1 & 5 & 3 & $10(27.0)$ & $8(21.6)$ \\
\hline Thrombocytopenia & 2 & 1 & 0 & 1 & $4(10.8)$ & $1(2.7)$ \\
\hline \multicolumn{7}{|l|}{ Laboratory test abnormalities } \\
\hline AST elevation & 2 & 1 & 1 & 0 & $4(10.8)$ & $1(2.7)$ \\
\hline ALT elevation & 2 & 2 & 0 & 0 & $4(10.8)$ & $0(0.0)$ \\
\hline \multicolumn{7}{|l|}{ Non-hematologic } \\
\hline Constipation & 15 & 0 & 0 & 0 & $15(40.5)$ & $0(0.0)$ \\
\hline Diarrhea & 4 & 0 & 0 & 0 & $4(10.8)$ & $0(0.0)$ \\
\hline Stomatitis & 3 & 2 & 0 & 0 & $5(13.5)$ & $0(0.0)$ \\
\hline Nausea/vomiting & 9 & 1 & 1 & 0 & $11(29.7)$ & $1(2.7)$ \\
\hline Fatigue & 7 & 2 & 0 & 0 & $9(24.3)$ & $0(0.0)$ \\
\hline Anorexia & 9 & 0 & 0 & 0 & $9(24.3)$ & $0(0.0)$ \\
\hline Dysgeusia & 6 & 0 & 0 & 0 & $6(16.2)$ & $0(0.0)$ \\
\hline Arthralgia & 7 & 0 & 0 & 0 & 7 (18.9) & $0(0.0)$ \\
\hline Myalgia & 11 & 1 & 0 & 0 & $12(32.4)$ & $0(0.0)$ \\
\hline Peripheral motor neuropathy & 3 & 4 & 0 & 0 & 7 (18.9) & $0(0.0)$ \\
\hline Peripheral sensory neuropathy & 20 & 12 & 2 & 0 & $34(91.9)$ & $2(5.4)$ \\
\hline Alopecia & 5 & 1 & 0 & 0 & $6(16.2)$ & $0(0.0)$ \\
\hline Pruritus & 6 & 4 & 0 & 0 & $10(27.0)$ & $0(0.0)$ \\
\hline
\end{tabular}

AST, Aspartate aminotransferase; ALT, alanine aminotransferase.

PTX as second-line CT for unresectable or recurrent GC has not yet been clinically evaluated. In a phase-II study, nabPTX given at $260 \mathrm{mg} / \mathrm{m}^{2}$ every 3 weeks as a second-line CT for previously 5-FU-treated unresectable or recurrent $\mathrm{GC}$ resulted in a $27.6 \%$ ORR, a median PFS of 2.9 months and OS of 9.2 months (11). Our data indicate that $n a b$-PTX as a second-line CT gave a $24.3 \%$ ORR, a median PFS of 4.8 months and OS of 10.4 months, comparable to the phase-II study. Moreover, one patient $(1.9 \%)$ had a CR in the phaseII study (11), whereas four patients (10.8\%) unexpectedly had CRs in this study. Based on these findings, nab-PTX seemed be an effective second-line drug in clinical practice.

Our data also showed that number of treatment cycles of $n a b$-PTX is the only independent factor for longer PFS. Adverse events led to dose reductions in 13 (35\%) patients and delays in $16(43 \%)$ patients in this study. However, the number of treatment cycles but not RDI, of which this study had a relatively high rate (median: $90 \%$ ), was associated with better PFS. Therefore, continuing to treat patients who responded to $n a b$-PTX therapy for a longer time while attending adverse events in a timely manner (even if dose reductions or delays are needed) seems critical to its efficacy. However, thus managed, weekly nab-PTX regimens may be expected to be similar to weekly PTX regimens. Currently, the non-inferiority of triweekly $\left(260 \mathrm{mg} / \mathrm{m}^{2}\right)$ or weekly $(100$ $\mathrm{mg} / \mathrm{m}^{2}$ ) $n a b$-PTX to weekly PTX used as a control arm in terms of OS is being evaluated to establish the appropriateness of nab-PTX as second-line CT for unresectable or recurrent $\mathrm{GC}$ in the ABSOLUTE trial, a phase-III study (14).

This study found no significant hypersensitivity or anaphylactic reactions were induced by nab-PTX therapy without premedication, similar to the phase-II study. Reasons for treatment withdrawal were mainly disease progression (97\%); one patient (3\%) discontinued the treatment because of grade 4 thrombocytopenia. Although grade 3 or 4 toxicities such as neutropenia and leukopenia were found, these adverse events were clinically managed. Especially, the most common grade 1-3 toxicities were anemia (97.3\%) and peripheral sensory neuropathy $(91.9 \%)$. Anemia might be affected by not only adverse events but also postgastrectomy complication or tumor bleeding in patients with unresectable or recurrent GC. All such cases were wellmanaged in this study, as they were all grade 1 or 2 toxicities. However, grade 2-3 peripheral sensory neuropathy remains an important problem that might be controlled by dose reductions and delays before the symptoms worsen. In this study, grade 2-3 peripheral sensory neuropathy led to 
dose reductions in $7(19 \%)$ patients and delays in $10(27 \%)$ patients. Ohno et al. have reported that both compression therapy using stockings and sleeves, and medication therapy using selected prophylactic drugs (such as goshajinkigan or mecobalamin) improve the grade of peripheral neuropathy by controlling microcirculation for breast cancer patients treated with $n a b$-PTX (15). Referring to this study, we also applied this therapy for unresectable or recurrent GC patients treated with $n a b$-PTX and some patients appeared to improve their grade of peripheral neuropathy.

In conclusion, $n a b$-PTX may become an effective therapy to prevent disease progression when used as second-line CT, by prolonging the number of treatment cycles and managing adverse events, even if requiring dose reductions or delays. Even though the current retrospective study was performed at a single center in a limited patient population and was therefore subject to selection bias, our findings should stimulate further inquiry into how to manage unresectable or recurrent $\mathrm{GC}$ in patients treated with $n a b$-PTX as second-line CT.

\section{References}

1 Ferlay J, Soerjomataram I, Dikshit R, Eser S, Mathers C, Rebelo M, Parkin DM, Forman D and Bray F: Cancer incidence and mortality worldwide: sources, methods and major patterns in GLOBOCAN 2012. Int J Cancer 136: E359-386, 2015.

2 Koizumi W, Narahara H, Hara T, Takagane A, Akiya T, Takagi M, Miyashita K, Nishizaki T, Kobayashi O, Takiyama W, Toh Y, Nagaie T, Takagi S, Yamamura Y, Yanaoka K, Orita H and Takeuchi M: S-1 plus cisplatin versus S-1 alone for first-line treatment of advanced gastric cancer (SPIRITS trial): a phase III trial. Lancet Oncol 9: 215-221, 2008.

3 Thuss-Patience PC, Kretzschmar A, Bichev D, Deist T, Hinke A, Breithaupt K, Dogan Y, Gebauer B, Schumacher G, Reichardt PThuss-Patience PC, Kretzschmar A and Bichev D: Survival advantage for irinotecan versus best supportive care as secondline chemotherapy in gastric cancer-a randomised phase III study of the Arbeitsgemeinschaft Internistische Onkologie (AIO). Eur J Cancer 47: 2306-2314, 2011.

4 Kang JH, Lee SI, Lim DH, Park KW, Oh SY, Kwon HC, Hwang IG, Lee SC, Nam E, Shin DB, Lee J, Park JO, Park YS and Lim HY: Salvage chemotherapy for pretreated gastric cancer: a randomized phase III trial comparing chemotherapy plus best supportive care with best supportive care alone. J Clin Oncol 30: 1513-1518, 2012.

5 Ford HE, Marshall A, Bridgewater JA, Janowitz T, Coxon FY, Wadsley J, Mansoor W, Fyfe D, Madhusudan S, Middleton GW, Swinson D, Falk S, Chau I, Cunningham D, Kareclas P, Cook N, Blazeby JM and Dunn JA: Docetaxel versus active symptom control for refractory oesophagogastric adenocarcinoma (COUGAR-02): an open-label, phase 3 randomised controlled trial. Lancet Oncol 15: 78-86, 2014.
6 Hironaka S, Zenda S, Boku N, Fukutomi A, Yoshino T and Onozawa Y: Weekly paclitaxel as second-line chemotherapy for advanced or recurrent gastric cancer. Gastric Cancer 9: 14-18, 2006.

7 Yamada Y, Shirao K, Ohtsu A, Boku N, Hyodo I, Saitoh H, Miyata $\mathrm{Y}$ and Taguchi T: Phase II trial of paclitaxel by threehour infusion for advanced gastric cancer with short premedication for prophylaxis against paclitaxel-associated hypersensitivity reactions. Ann Oncol 12: 1133-1137, 2001.

8 Kodera Y, Ito S, Mochizuki Y, Fujitake S, Koshikawa K, Kanyama Y, Matsui T, Kojima H, Takase T, Ohashi N, Fujiwara M, Sakamoto J and Akimasa N: A phase II study of weekly paclitaxel as second-line chemotherapy for advanced gastric Cancer (CCOG0302 study). Anticancer Res 27: 2667-2671, 2007.

9 Yamaguchi K, Tada M, Horikoshi N, Otani T, Takiuchi H, Saitoh S, Kanamaru R, Kasai Y, Koizumi W, Sakata Y and Taguchi T: Phase II study of paclitaxel with 3-h infusion in patients with advanced gastric cancer. Gastric Cancer 5: 90-95, 2002.

10 Hironaka S, Ueda S, Yasui H, Nishina T, Tsuda M, Tsumura T, Sugimoto N, Shimodaira H, Tokunaga S, Moriwaki T, Esaki T, Nagase M, Fujitani K, Yamaguchi K, Ura T, Hamamoto Y, Morita S, Okamoto I, Boku N and Hyodo I: Randomized, openlabel, phase III study comparing irinotecan with paclitaxel in patients with advanced gastric cancer without severe peritoneal metastasis after failure of prior combination chemotherapy using fluoropyrimidine plus platinum: WJOG 4007 trial. J Clin Oncol 31: 4438-4444, 2013.

11 Sasaki Y, Nishina T, Yasui H, Goto M, Muro K, Tsuji A, Koizumi W, Toh Y, Hara T and Miyata Y: Phase II trial of nanoparticle albumin-bound paclitaxel as second-line chemotherapy for unresectable or recurrent gastric cancer. Cancer Sci 105: 812-817, 2014.

12 Sobin LH, Gospodarowicz MK and Wittekind CH: TNM Classification of Malignant Tumours. Seven Edition. Oxford: Wiley-Blackwell, 2009.

13 Japanese Gastric Cancer Association. Japanese classification of gastric carcinoma: Third English edition. Gastric Cancer 14: 101-112, 2011.

14 Koizumi W, Morita S and Sakata Y: A randomized Phase III trial of weekly or 3-weekly doses of nab-paclitaxel versus weekly doses of Cremophor-based paclitaxel in patients with previously treated advanced gastric cancer (ABSOLUTE Trial). Jpn J Clin Oncol 45: 303-306, 2015

15 Ohno T, Mine T, Yoshioka H, Kosaka M, Matsuda S, De Kerckhove M, De Kerckhove C, Irie J, Inoue K, Haraguchi M, Kitajima M, Shinichiro I, Tokai H, Tanaka T and Izumida R: Management of peripheral neuropathy induced by nab-paclitaxel treatment for breast cancer. Anticancer Res 34: 4213-4216, 2014.

Received October 26, 2016

Revised November 9, 2016 Accepted November 14, 2016 